\title{
Microsculpture Exact Description of the Isolation of Some Types of Beetles Weevils Family (Curculionidae) in Iraq
}

\author{
Sadoon Ibrahim Ismail \\ University Al, Mustansiryiah Faculty of Basic Education/Baghdad, Baghdad, Iraq
}

\begin{abstract}
It was isolated eleven species of weevils family (Curculionidae) back to Subfamiles are Brachyderinae, Cleoninae, depending on the exact Microsculpture of the pits on elytra of these types, namely, Bothynoderes memosae, Tanymecus sp., Cleonus orratus, Larinus maculosus, Lixus sp., Hypera sp., Amnocleonus hiroglyphicus, Bangasternus planifrons, Phacephorus nubeculosus, Coniocleonus puseudooldiquus, Tanymecus insipidus.
\end{abstract}

Key words: Elatron of coleoptera, microsculpture, curculionidae, isolation types.

\section{Introduction}

Beetles weevils Family is one of the largest families Imms [1] Prevalent in the world and the first to launch the term beetles weevils family Curculionidae is the Leach 1817, Essig [2]. And its importance is clear that the economic impact on the plants Shafik [3]. Most of these insects have day activity (Dieurnal). And mostly when its sense of danger has legs and Antennae detection to her body and herself fall to the ground and remain static. It also takes color where you live Borrore and Delong [4].

\section{Materials and Methods}

The specimen put it in a glass (Beaker) loo $\mathrm{ml}$ containing water and half of it floating cork and proved them covered petri dish beaker. Then put the beaker on the heat source to heat the water 50-60 c. to soften parts of the body and easily separated [5]. To soften parts of the body and easily separated, elytra were separated to put it on a slide under compound microscope that contains the ocular

Corresponding author: Sadoon Ibrahim Ismail, Ph.D., assistant professor, research field: zoology and entomology. E-mail: sadoonalbiaty@yahoo.com. micrometer kind for the purpose of examining the microsculpture of the species. Keys were used to isolate the species Shafik [6, 7]. Models and compared species preserved in the natural history museum of the University of Baghdad.

\section{Results and Discussion}

Microsculpture is used to dscribe the exact species but not use the adjective from which to isolate the species. In this research it was used to isolate eleven species from family Curculionidae belonging to the Subfamily: Brachyderinae and cleoninae.

Microsculpture has been taking from elytra of three regions of base, and central and Apex.

It shows the presence of large variation among the same species and between species.

\subsection{Tanymecus Insipidus Fig. 1}

It features the Microsculpture at the base of the rectangle and from growths at the corners with cuticle focus at the center.

The center is smaller than basal rectangular infinity when angle and concentration cuticle less. But at the apex, which shall be smaller than the last square shape with few cuticle. 
(Curculionidae) in Iraq

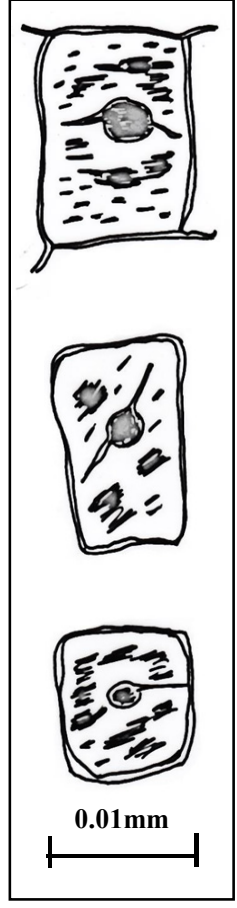

Fig. 1 Tanymecus insipidus.

\subsection{Bothynoderes Memosae Fig. $2 a$}

The microsculpture at the base in acircle shows thick aspects and center with a whole strips of cuticle. The middle shape irregularly concentrated in the center cuticle.

But at the top that small circular shape almost edge wide holds most of the center cuticle.

\subsection{Tanymecus sp. Fig. $2 b$}

At the top are large circular bar at the top of cuticle as well as from the bottom is also concentrated in the center. The middle her semi-circular strips extending from the inner edge and in the center there are few central cuticle either that at the top of the elytron shall be almost small circular and cuticle be in the form of strips and internal points and the biggest part at Middle.

\subsection{Cleonus Orratus Fig. $3 a$}

Elaytron base in large semi-circular cuticle occupies most of the middle and the remaining points. But it is with a circular center and scattered around points cuticle.

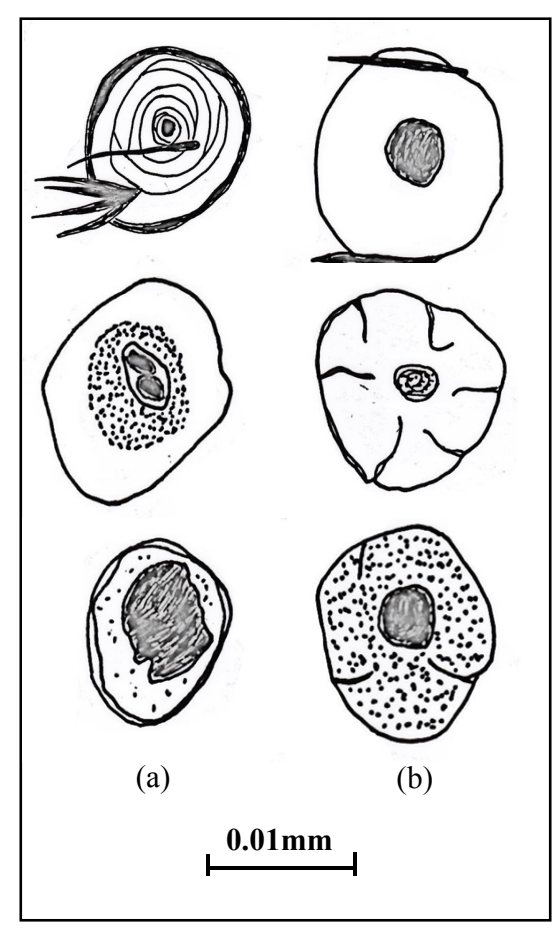

Fig. 2 a-Bothynoderes memosae, $b$-Tanymecussp.

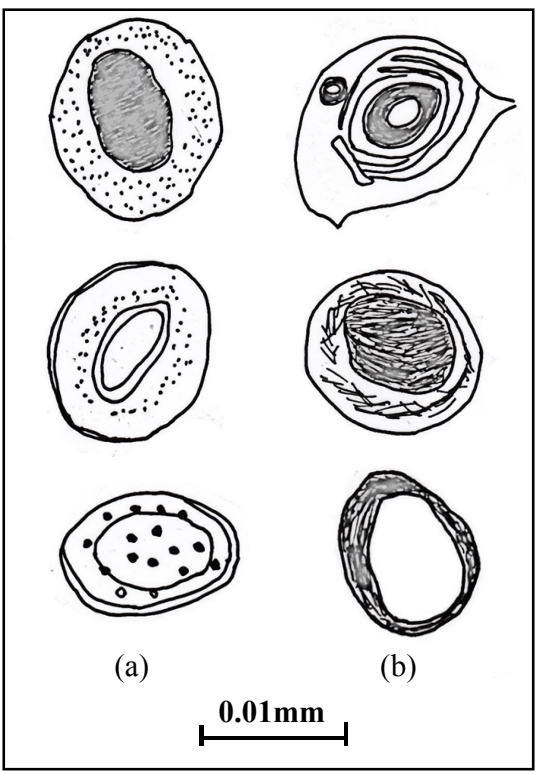

Fig. 3 a-Cleonus orratus, $b-$ Larinus maculosus.

The abex in the elytron is made up several departments and scattered inside points of cuticle.

\subsection{Larinus Maculosus Fig. $3 b$}

At the base are large, overlapping circles adorned with cuticle, the middle circular shape occupy mostly cuticle. But at the apex, which are circle at margin there cuticle. 


\subsection{Lixus sp. Fig. $4 a$}

Microsculpture at the exact elytron base large square shape almost and the cuticle stationed at aspects and the center. The microsculpture in the middle of the elytron almost rectangular in shape and there are aspects and cuticle at the center and spread in the vacuum the rest in the form of filaments. The form at the apex are smaller than the square Shape the rest is spread almost cuticle at the edges and the center and the space around the center and be less dense than the median and basal.

\subsection{Hypera sp. Fig. $4 b$}

At the base are large circular cuticle is concentrated at the center and some aspects of moderation and be semi-circular stands at cuticle. At the apex of the elytron be exact microsculpture small semi-circular cuticle stationed in the center and one of the aspects and spreads her free.

\subsection{Amnocleonus Hiroglyphicus Fig. $5 a$}

Microsculpture to be exact when the elytron base consists of geometric forms adorned cuticle. The center of the elytron adorned cuticle be smaller than the last, and like them very much. But at the apex, which shall be in the form of small circles adorned cuticle.

\subsection{Bangasternus Planifrons Fig. $5 b$}

It turns out that the exact Microsculpture at the base, middle and apex of the elytron almost the same size and shape of the first and second circulay and third almost rectangular include acircle and the cuticle few except the microsculpture at the apex there cuticle shaped bar at the edge.

\subsection{Phacephorus Nubeculosus Fig. $6 a$}

Microsculpture note when a large elytron base and square shape and cuticle there at the edges and close to the center in the midst of the elytron be avoid Microsculpture and cuticle in the form of tapes and

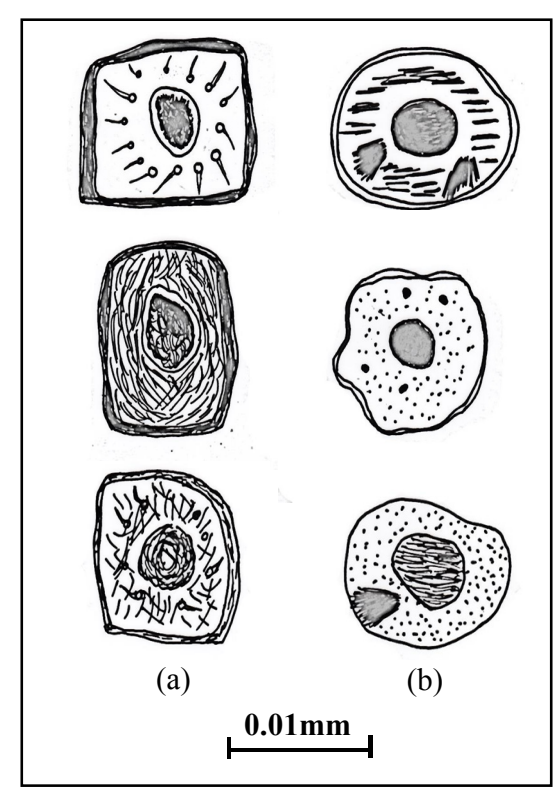

Fig. 4 a-Lixus sp. b-Hypera sp.

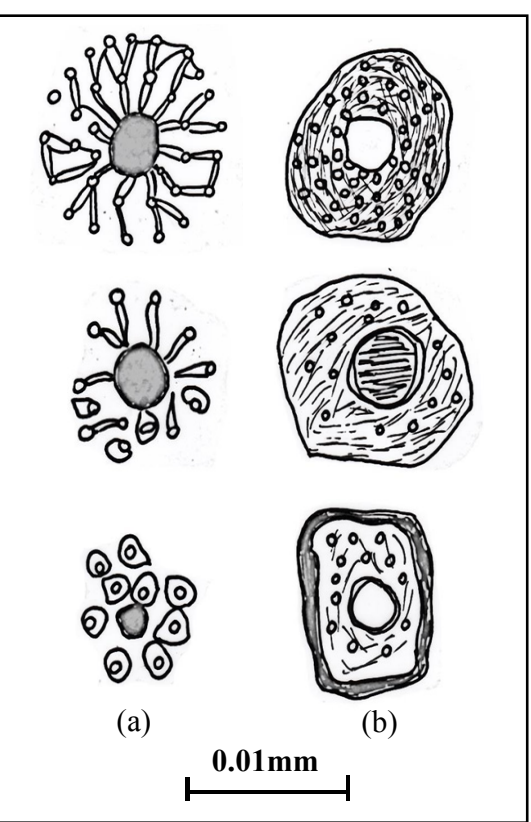

Fig. 5 a-Amnocleonus hiroglyphicus b-Bangasterernus planifrons.

sculpture in a small circular top and cuticle in the form of an average bar.

\subsection{Coniocleonus Pseudoobliquus Fig. $6 b$}

Microsculpture in this species at the base is large circular shape and concentrated cuticle at its edge either Microsculpture in the center is almost rectangular in shape and there are cuticle at the edges and a little in the middle and the Microsculpture at the 


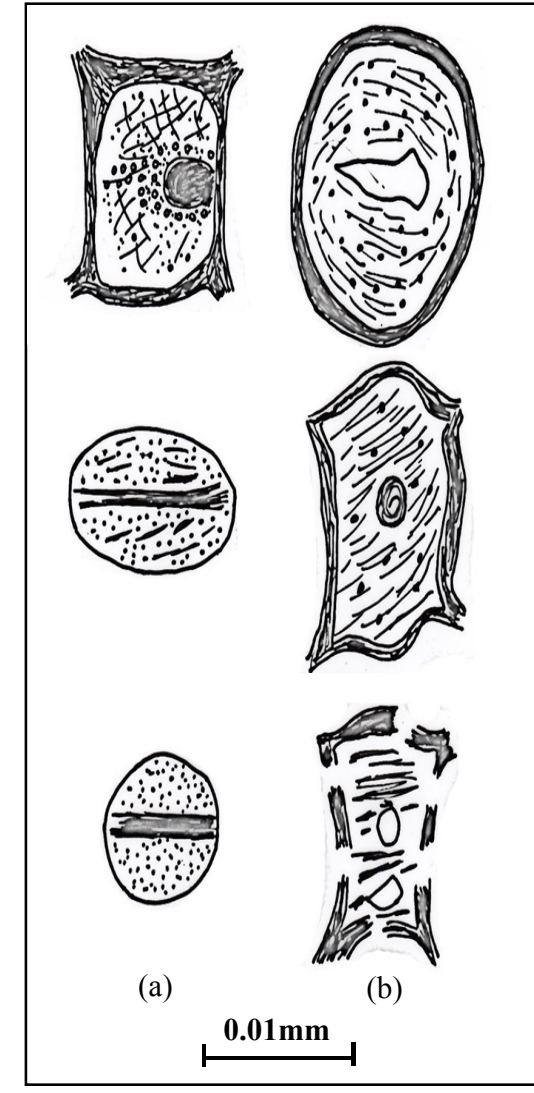

Fig. 6 a-phacephorus nubeculosus b-Coniocleonus pseudobliquus. apex alittle Sculpture smallest in the center its borders are not connected and concentrated by cuticle.

\section{References}

[1] Imms, A. D. 1988. A General Textbook of Entomology. vol. 1, 2 classification and Biology. London. Methuen and Co, Ltd, New York.

[2] Essig, E. O. 1947. College Entomology. New York. The Macmillan, Co.

[3] Shafik, I. H. 1988. Studies on the Curculionidae Insects (Coleoptera) Ph.D. thesis, Faculty of Agriculture, University of Alexandria.

[4] Borror, D. J., and Delong, D. M. 1976. An introduction to study of insects. New Yoyr, Rinehart and Co. fourth edition.

[5] Ismail, S. I. 1983. Taxonomic study on the Longhorned Borer Beetles Cerambycidae coleoptera of Iraq. M.S. thesis. Faculty of Science university of Baghdad. 199. pp.

[6] Shafik, I. H. 1977. Keys to genera and species of families. Curculionidae, Scolytidae of Iraq. Part III, Min Agr. Ref. Dir. Gen. Por. 10 p.

[7] Salih, Israa Mahdi. 2007. Taxonoic study of Some species the two subfamilies: Brachyderinae and Cleoninae (Coleoptera :Curculionidae) in some region of Iraq M.S. thesis. Faculty of Basic Education University of Al-Mustansiriayiah. 